\title{
La protección de la biodiversidad en la práctica: intervención de la Administración Local. El caso de Tenerife, Islas Canarias
}

\author{
Víctor M. García Díaz ${ }^{1}$
}

Sumario: 1. LAS TRES SOSTENIBILIDADES Y LOS TRES CAPITALES. 2. LA ARMONIZACIÓN ENTRE LOS TRES PRINCIPALES CENTROS DE PODER. 3. EL ÁREA DE MEDIO AMBIENTE DEL CABILDO INSULAR DE TENERIFE. 3.1. Sistemas complejos, control de flujos y eficiencia. 3.1.1. Teoría de sistemas. 3.1.2. Teoría del Control de Flujos. 3.1.3. Teoría del caos y la complejidad. 3.2. Fases del proceso organizativo del Área de Medio Ambiente. 3.2.1. Diagnóstico inicial. 3.2.2. Formulación de la propuesta de reforma de la estructura orgánica y medios. 3.2.3. Definición de los puntos de control del sistema. 3.2.4. Diseño del sistema de gestión del Área. 4. LOS TRES ELEMENTOS BÁSICOS DE LA GESTIÓN ADMINISTRATIVA. 4.1. Una estructura orgánica. 4.2. Una tecnología y unos medios modernos. 4.3. Un sistema de gestión. 4.3.1. Los procedimientos del sistema de gestión. 4.3.2. La organización documental del sistema de gestión. 4.3.3. Principio de la mejora continua. 5. LA GESTIÓN: ORGANIZACIÓN Y FUNCIONES DEL ÁREA. 5.1. Qué: Competencias del Área de Medio Ambiente. 5.1.1. Conservación, manejo y aprovechamiento de recursos naturales y culturales. 5.1.2. Políticas recreativa y educativa de la naturaleza. 5.1.3. Desarrollo socioeconómico de las poblaciones. 5.2. Cómo: Modos de intervención de la Administración para cumplir sus competencias. 5.2.1. Planificación y ordenación. 5.2.2. Policía y garantía de la legalidad. 5.2.3. Fomento, gestión y servicios. 5.3. Quién: Estructura orgánica del Área de Medio Ambiente. 5.3.1. Unidades Territoriales. 5.3.2. Unidades Insulares. 5.3.3. Unidades estructurales o centrales. 6. EL SEGUIMIENTO Y LA EVALUACIÓN. 6.1. Necesidad del seguimiento y la evaluación. 6.2. El sistema de seguimiento y evaluación del Área de Medio Ambiente. 6.2.1. Nivel 1: Seguimiento de los planes ejecutados por el Área (incluyendo los planes de espacios naturales protegidos). 6.2.2. Nivel 2: Seguimiento del Plan Anual de Actividades. 6.2.3. Nivel 3: Criterios de calidad (eficiencia). 6.2.4. Nuevos campos de trabajo en materia de seguimiento. BIBLIOGRAFÍA.

1 Responsable de la Unidad Planificación, Coordinación Técnica y Control de Gestión del Área de Medio Ambiente del Excmo. Cabildo Insular de Tenerife. 
Nuestro planeta, esa gran planta de reciclado alimentada por energía solar, que para su funcionamiento sostenido experimenta internamente múltiples procesos de carácter cíclico (ciclos biogeoquímicos, ciclos de vida de las especies, etc.), presenta en su conjunto una elevada sensibilidad al desbordamiento de las fuentes y sumideros en los que se apoyan dichos ciclos (V. Millenium Ecosystem Assessment Panel, 2005). En esta línea, el principio fundamental que debería cumplir toda civilización y toda economía es que no se puede marchar más deprisa que la naturaleza o, en otras palabras, la velocidad de proceso entre las entradas y las salidas del susbsistema humano no puede superar la velocidad de proceso del sistema global de la biosfera (Daly, 2005).

\section{FIGURA 1}

Diferentes proyecciones del índice de bienestar humano, según las medidas económicas globales que se tomen

\section{Bbentar humano}

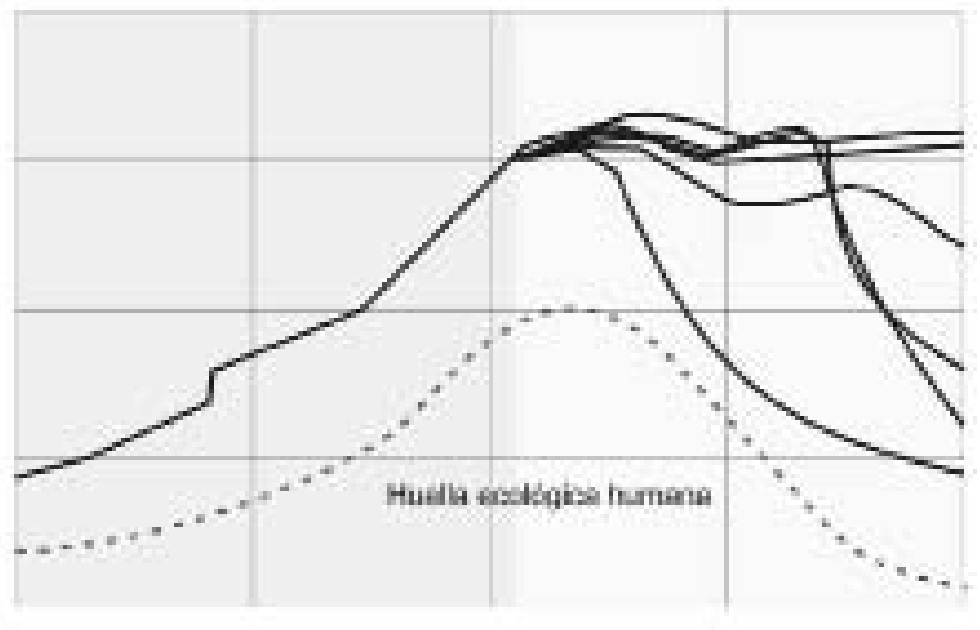

Fuente: Los límites del crecimiento 30 años después.

Los autores de uno de los primeros documentos que advirtieron la merma alarmante de los recursos naturales, el conocido informe Los Límites del Crecimiento, elaborado en 1972 por encargo del Club de Roma, han realizado ya dos revisiones de su obra. En la última de ellas, Los Límites del Crecimiento, 30 años después (2004), dejan claro, con la aplicación de un modelo informático (World3) que, de no tomar medidas drásticas y rápidas, se plantea un colapso de la economía y la civilización en muy poco tiempo (V. figura 1, donde se dibujan diversas posibilidades de evolución del denominado índice de bienestar humano, varias de ellas conducentes a un colapso más o menos próximo en tres o cuatro décadas, y en todo caso, antes del año 2100).

Tres son los tres problemas básicos, estructurales, que plantean estos autores 380 (Meadows, Randers y Meadows, 2004): 
1. Los límites de La Tierra -fuentes de recursos y sumideros de emisiones/residuos- son finitos pero, además, erosionables: La Tierra ya ha sufrido la merma de sus límites de 1972, al haberse deteriorado suficientemente sus recursos, ciclos y procesos. Gran cantidad de recursos no renovables han sido agotados, y de los renovables, muchos no tienen ya la capacidad de regeneración original, por el deterioro de los elementos básicos de sus ecosistemas de soporte (suelos, vegetación, clima local, etc.)

2. La especie humana pugna por una búsqueda incesante de crecimiento, un crecimiento exponencial de muy baja ecoeficiencia que desborda los límites. Ningún sistema finito puede sufrir un consumo creciente de sus recursos por parte de una especie que crece exponencialmente tanto en sus efectivos como en sus demandas materiales.

3. Hay un desfase en la respuesta de la civilización ante la proximidad de los límites, es decir, una respuesta tardía ante los avisos. Seguimos fiándonos y pensando bajo las mismas claves que el economista clásico David Ricardo a principios del XIX: confiamos en la inventiva de la especie humana y su capacidad para introducir nuevas tecnologías que resuelvan los problemas, pero la velocidad de los acontecimientos supera la capacidad de respuesta humana convencional y las inercias de su modelo económico.

El agotamiento de los recursos naturales, en términos económicos convencionales, significa que se producirá escasez, que terminará por convertirse en inflación y estancamiento (estanflación, el término acuñado en los años 70). Por si fuera poco, la fase anterior a este fenómeno final, ejerce un efecto perverso que acelera la llegada del colapso: el enrarecimiento de una materia prima eleva su precio en el mercado, lo que hace rentable explotar yacimientos de ella que antes no lo eran y el agotamiento de los recursos se precipita aun más. Es el caso del petróleo con la subida de precios de los años 70, en que comenzó a ser rentable explotar el Mar del Norte, las arenas bituminosas de Canadá y otros muchos. A este ritmo se corre el peligro cierto de entrar en una situación de probable no retorno, porque no se tratará ya de una de las tradicionales crisis de carácter financiero, de falta de liquidez monetaria o de estallido de burbujas económicas, sino de una crisis ambiental, el tipo de recesión verdaderamente limitante y catastrófica, el fin de nuestra economía tal y como la conocemos hoy, donde no servirán ya las políticas fiscales ni monetarias, ni la regulación ni el control financieros.

\section{LAS TRES SOSTENIBILIDADES Y LOS TRES CAPITALES}

El sistema económico humano, que es sólo un subsistema del sistema biosfera, debe integrarse en la velocidad de los ciclos de ésta, para no llegar a imposibilidades biofísicas que conduzcan al colapso. La conclusión obvia es que la gestión del patrimonio natural, del capital natural, no se puede hacer desligada de la economía, del capital económico, razón por la que la Administración Ambiental no puede organizar la gestión y conservación del patrimonio natural sólo centrándose en la acción directa sobre la biodiversidad y los recursos naturales. 
Pero aún existe un tercer factor, un tercer y decisivo tipo de capital a conjugar con los otros dos: dado que el problema ambiental es de origen antrópico y no otro, los esfuerzos que la Administración pueda plantear para resolver la cuestión de la insostenibilidad, no serán nunca suficientes sin el compromiso de participación concienciada y voluntaria de la ciudadanía, es decir, de los propios humanos que causamos el problema. No optimizaremos el uso de los capitales económico y natural, sin incorporar el capital social, que consiste precisamente en el grado de participación, el asociacionismo, el voluntariado, la solidaridad y la cohesión social, en definitiva, el asumir los retos ambientales y colaborar en su resolución mostrando conductas tanto individuales como colectivas orientadas a lograr el beneficio de la comunidad y de los individuos que la componen, lo que se traduce en conseguir una democracia participativa frente a la representativa imperante, que se preocupe de cuidar La Tierra para sí y para los que han de venir.

Como resumen de este apartado y para sentar el primer principio esencial de toda organización administrativa ambiental hay que afirmar que la sostenibilidad sólo es posible si se produce en los tres órdenes: ambiental, económico y social, poniendo en valor sus tres capitales asociados, un enunciado sobradamente conocido que queda representado en la figura 2 , en forma de engranajes, que simbolizan la necesidad de integración de los tres aspectos de la actividad humana, símil didáctico que se repetirá a lo largo del presente documento para simbolizar otros principios que se entienden fundamentales para la organización administrativa ambiental.

\section{FIGURA 2}

\section{Principio de la triple sostenibilidad}

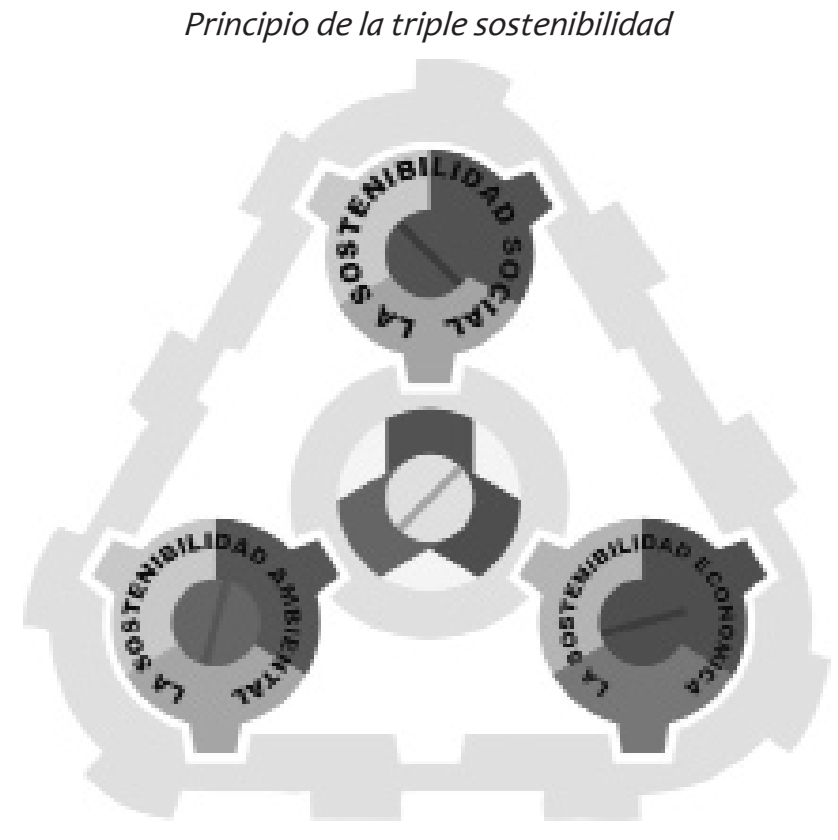

Documentación Administrativa 


\section{LA ARMONIZACIÓN ENTRE LOS TRES PRINCIPALES CENTROS DE PODER}

Y para conseguir esta integración de objetivos ambientales, económicos y sociales, no queda otro recurso que el de lograr que todos los poderes de la sociedad trabajen enlazados y coordinados, compatibilizando sus objetivos particulares. Tres son los centros de poder principales que deben aunar sus fuerzas: los poderes públicos, que han de trabajar en estrecho contacto con los agentes económicos, motores del progreso, el empleo y el estado de bienestar, y con la sociedad civil, siendo ésta un sector muy amplio pero que debe ser contemplado y valorado en su totalidad, evitando que quede eclipsado ninguno de sus subsectores por el papel de los grupos de mayor peso e influencia, como los medios de comunicación o los agentes sociales (figura 3).

Y éste es el segundo principio esencial a tener en cuenta para trabajar desde la Administración Ambiental: buscar la integración en un trabajo común y coordinado de estos tres centros de poder.

\section{FIGURA 3}

\section{La necesaria integración de los tres centros de poder}

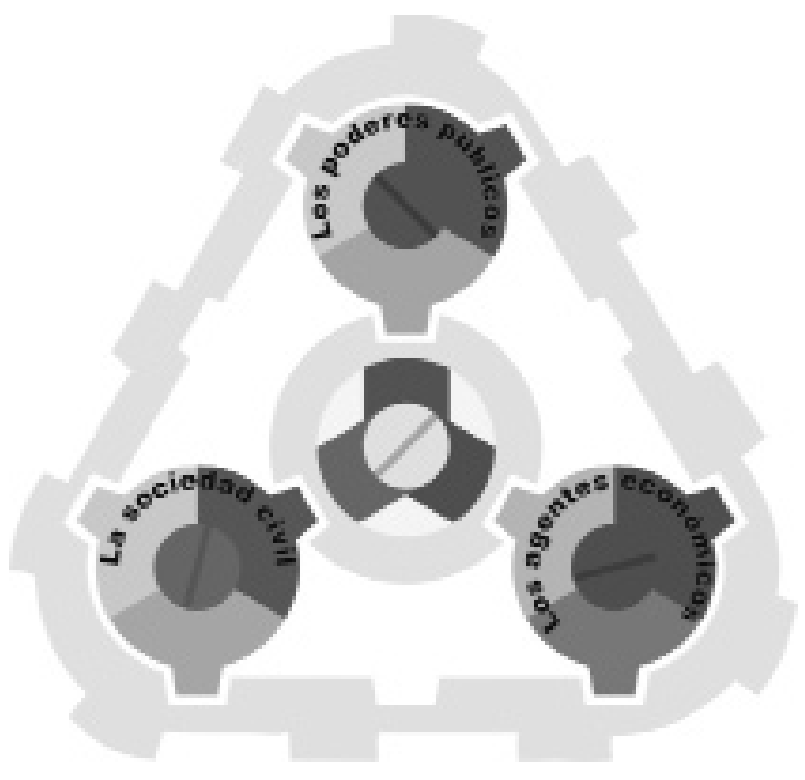

\section{EL ÁREA DE MEDIO AMBIENTE DEL CABILDO INSULAR DE TENERIFE}

\section{Intentando poner en práctica los principios hasta ahora enunciados y otros que se referirán a continuación, el Área de Medio Ambiente del Cabildo Insular de Teneri-}


fe, ha configurado su estructura y funcionamiento, cuya descripción será objeto del presente y sucesivos epígrafes. La metodología y las conclusiones generales pueden ser perfectamente trasladables al diseño organizativo en otras Administraciones.

El Área de Medio Ambiente, que dispone de más de 600 personas, tiene como ámbito de responsabilidad todo el territorio de la isla de Tenerife (salvo en algunas materias dentro del Parque Nacional del Teide), y sus competencias han quedado configuradas a partir de funciones propias asumidas desde la condición de Administración Local, junto a las que se han venido traspasando sucesivamente desde la Comunidad Autónoma de Canarias (gestión y conservación de espacios naturales protegidos, servicios forestales, protección del medio ambiente, caza y vías pecuarias y pastos). A todas ellas se añaden diversas competencias establecidas en normas de rango legal y reglamentario, como las Leyes de Ordenación del Territorio de Canarias, de Residuos de Canarias o de Medidas Urgentes en Materia de Ordenación Territorial para la Dinamización Sectorial y la Ordenación del Turismo.

A partir del panorama competencial asumido y del personal y medios materiales y económicos a su cargo, el Cabildo Insular, por acuerdo del Pleno de la Corporación, en julio de 2001, aprueba la estructura orgánica y funciones del Área de Medio Ambiente, trabajo que ha continuado completándose hasta la actualidad. Para llegar a ese punto, se tuvo que desarrollar desde 1999, por un equipo técnico de las Áreas de Recursos Humanos y Medio Ambiente, un trabajo de varias fases, iniciado con un diagnóstico de la situación y continuado con una fase de diseño, que contó con la participación del personal del Área en reuniones y talleres que ayudaron a tomar las decisiones finales de organización.

\subsection{Sistemas complejos, control de flujos y eficiencia}

Tres teorías vienen a inspirar el procedimiento a seguir para la planificación organizativa del Área de Medio Ambiente, aunque son aplicables a muchos otros campos de la realidad, ya sean científicos, sociales, económicos. En nuestro caso, la organización administrativa, no precisa utilizar los desarrollos matemáticos de estas teorías, pero sus principios sí resultan perfectamente válidos y aplicables a nuestros propósitos.

\subsubsection{Teoría de sistemas}

Ampliamente conocida, en el caso presente se ha utilizado como base para la tipificación de procesos que ocurren dentro de la organización y para elaboración de los procedimientos necesarios con los que regular y optimizar el funcionamiento de aquéllos. Simplemente, se trata de considerar al Área como un sistema, con entradas y salidas, entre las que suceden una serie de procesos internos facilitados por los elementos del sistema. 
Las salidas del sistema serán los productos que genera el Área de Medio Ambiente, ya sean éstos la construcción de un mercadillo en un parque rural, la autorización para un aprovechamiento forestal, la sanción por una infracción ambiental, el manual de educación ambiental para un aula de la naturaleza o un plan insular de uso público.

\section{FIGURA 4}

Los principios de las tres teorías se articulan para inspirar el proceso organizativo del Área de Medio Ambiente

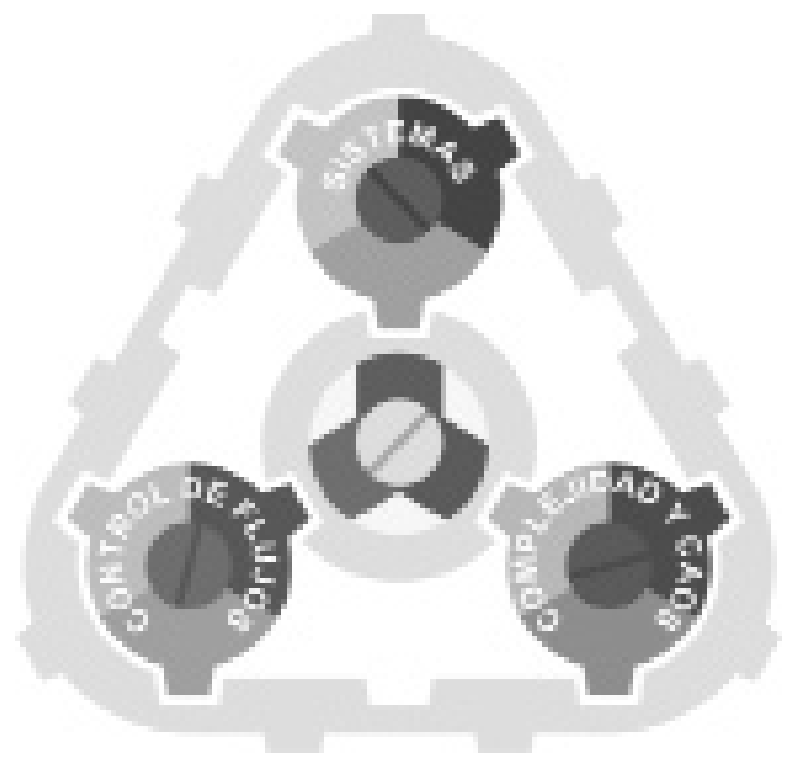

Las entradas del sistema son las fuentes, los estímulos que permiten el arranque de un proceso hasta conseguir unos productos finales o salidas del sistema. Si el producto buscado es una autorización, las entradas son la solicitud del interesado y la información necesaria para resolver; si el producto buscado es la construcción de un vivero contemplado en un plan forestal, las entradas son el presupuesto necesario y el propio plan que lo establece.

Los elementos del sistema son de diversa índole: unidades administrativas, personal, órganos resolutorios, etc., y los procesos son todos los pasos, todas las acciones que operan desde las entradas hasta las salidas. En el apartado 4.3.1. se muestra el ejemplo del Sistema Autorizaciones/Informes/Evaluación de Impacto, un macroproceso concreto para el que se detallan entradas, salidas, elementos y procesos que ilustran lo expuesto hasta aquí. Esta descripción escrita de quién y cómo debe realizar cada paso de un proceso es lo que se denomina procedimiento. 


\subsubsection{Teoría del control de flujos}

Aunque fue enunciada desde el campo de la bioquímica (Heinrich, Rapoport y Rapoport, 1977), su aplicación puede alcanzar a cualquier materia donde intervengan flujos, ya sean éstos metabólicos, de tráfico rodado, de electricidad o de expedientes administrativos. Los flujos siguen una sucesión de fases e hitos que pueden ejercer distinta limitación sobre la velocidad y cantidad del flujo global del proceso de que se trate. Algunas de estas etapas son sensiblemente limitantes (cuellos de botella) y pueden controlar una gran parte o la mayoría de todo un proceso, de forma que operando pequeñas modificaciones sobre ellas se pueden obtener modificaciones sustanciales del flujo total. Todas las etapas tienen asociado un coeficiente de control. Cuanto mayor sea éste, mayor es la influencia de esa etapa sobre el flujo conjunto del proceso.

La dinámica administrativa es por su naturaleza una dinámica de flujos de procedimientos, ya sea para otorgar una autorización, para emitir un informe o para formalizar y ejecutar la contratación de una obra, estudio o servicio, y es determinante encontrar las fases limitantes, cuya alteración, por pequeña que sea, puede suponer una perturbación grande en todo el sistema, y los puntos de control sobre los que se puede operar fácilmente para ejecutar fluidamente los objetivos planteados o bien para reconducir cualquier problema del sistema, optimizando así su eficacia y eficiencia.

\subsubsection{Teoría del caos y la complejidad}

Más que una teoría, es una nueva ciencia o campo de investigación que cada vez cobra más implantación, y se relaciona con muchas disciplinas, desde la física o la ingeniería hasta la economía o la informática. Los sistemas complejos no evolucionan como los sistemas lineales y no son fácilmente predecibles. Es la razón de que los modelos de los economistas fallen tan a menudo o que las predicciones meteorológicas precisas no puedan realizarse más allá de unos pocos días.

Si los sistemas complejos rebasan el límite del caos, se vuelven muy sensibles a las condiciones iniciales, de forma que pequeños cambios en ellas resultan en grandes desviaciones del sistema (efecto mariposa de Lorenz) y se vuelven por ello inestables, no sometidos al azar propiamente pero difíciles de predecir a medio y largo plazo, pudiendo tender hacia atractores extraños, que son zonas de convergencia cambiantes en el tiempo. Cuando diseñamos y establecemos una organización, unas normas, unos procedimientos, es fundamental aplicar el principio de máxima simplicidad, en evitación de estas consecuencias que hacen difícilmente gobernable el sistema.

El Área de Medio Ambiente es un sistema complejo, es decir, las relaciones causa-efecto no siguen líneas independientes desde las entradas hasta las salidas del sistema, sino que estas líneas tienen interconexiones causa-efecto entre sí, así como bifurcaciones. Ello genera una situación en que los flujos no se producen en líneas estancas, sino que configuran una red, donde la acción en un elemento puede suponer cambios sensibles en muchas otras partes del sistema y no sólo en el flujo princi386 pal de la línea donde se halle ese elemento. 
FIGURA 5

Esquema de un sistema complejo

ENTRADAS

SALIDAS

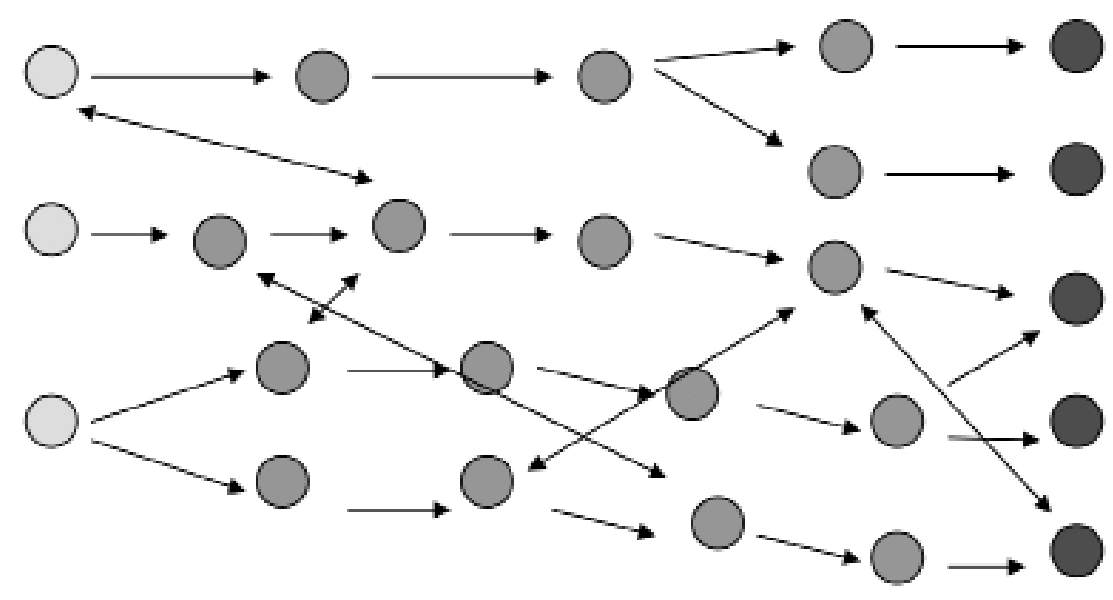

Elementos del sistema

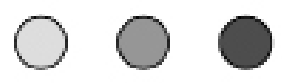

Pasos o etapas de los procesos del sistema

Para controlar un sistema complejo optimizando los recursos empleados, así como los tiempos invertidos en los procesos, y mejorando con ello las salidas, no se puede ejercer continuamente el control sobre cada uno de los elementos del sistema, porque emplearíamos más recursos y tiempo en ello que en el propio funcionamiento material de los procesos. Se trata, pues, de encontrar, de entre todos los elementos del sistema, cuáles pueden tener mayor influencia sobre los demás elementos y sus procesos de flujo asociados, y ejercer el control principal desde esos elementos clave. En el apartado 5.3.3. se describen los puntos de control que se definieron para la organización y funcionamiento del Área.

\subsection{Fases del proceso organizativo del Área de Medio Ambiente}

Con todas estas premisas y pasos previos, se plantearon diversas etapas en el camino a la organización del Área, que por orden sucesivo son: 


\subsubsection{Diagnóstico inicial}

El Diagnóstico Inicial es una fase esencial de todo proceso planificador de la gestión en una organización. En el caso que nos ocupa, estuvo basado en las siguientes tareas:

1. Tipificar todas las competencias del Área y sus procedimientos asociados, establecidos en la normativa o no.

2. Hacer inventario de la estructura orgánica preexistente, de los recursos humanos y medios materiales y económicos presentes, así como de las funciones y cualificación del personal.

3. Con esta información, elaborar el diagnóstico propiamente, basado en las siguientes variables extraídas del modelo EFQM de gestión de la calidad: Liderazgo, política y estrategia, personal, alianzas y recursos, procesos del sistema y resultados en los clientes y la sociedad.

Mediante este trabajo, se detectaron necesidades de mejora en los objetivos y estrategias, en la interpretación de las competencias asumidas, en la organización del personal, su jerarquía, cualificación y distribución de funciones, en el número de recursos humanos y materiales, en la planificación y control presupuestarios, en la coordinación administrativa dentro y fuera del Área y, en especial, en la eficacia de los procedimientos hasta entonces establecidos, muchas veces causa de disfunciones sobre los anteriores aspectos citados. Las decisiones que sobre la organización se tomaron obedecieron a una secuencia lógica de criterios que serán expuestos a continuación (apartados 3.2.2, 3.2.3. y 3.2.4.), mientras que los resultados a los que llevó su aplicación son presentados en los capítulos 4 y 5.

\subsubsection{Formulación de la propuesta de reforma de la estructura orgánica y medios}

De acuerdo con la fase de diagnóstico y con los objetivos marcados tras ella, se procedió a diseñar una propuesta de reforma de la estructura orgánica preexistente en el Área, con la reasignación de personal y medios necesarios. En este punto se definieron exhaustivamente las competencias de cada unidad, evitando absolutamente la superposición o solapamiento de estructuras o funciones, de forma que quedaron preconfigurados los puestos de trabajo y su organización en unidades administrativas, con descripción específica de las funciones, tanto de las unidades como de los puestos adscritos a ellas.

\subsubsection{Definición de los puntos de control del sistema}

De acuerdo con la Teoría del Control de Flujos, se definieron los elementos clave 388 de control del sistema, con lo que se realizaron los últimos retoques a la estructura 
orgánica pensada, quedando designadas en este paso las unidades administrativas de coordinación y control (V. apartado 5·3·3).

\subsubsection{Diseño del sistema de gestión del Área}

Aprobadas ya por el Pleno del Cabildo de Tenerife la nueva estructura orgánica y la relación de puestos de trabajo y medios del Área de Medio Ambiente, se pasó a definir un sistema de gestión (descrito en el apartado 4.3.), que contempla una política de gestión de calidad global del Área, así como un conjunto ordenado de procedimientos para regular y optimizar los procesos que operan dentro de ésta. Para ello se dibujó primero el mapa de procesos del Área y se tipificaron los pasos y etapas de cada uno, poniendo siempre como referente el principio de alineamiento estratégico de todas las unidades administrativas, es decir el deber de trabajo coordinado como un solo equipo para conseguir objetivos comunes por la organización en su conjunto.

\section{RESULTADOS}

Tras todo el trabajo de planificación expuesto, a continuación se presentan los resultados del sistema de organización adoptado y las claves que se estiman fundamentales para el funcionamiento de un departamento con competencias ambientales, trasladables también a otros tipos de instancias administrativas.

\section{LOS TRES ELEMENTOS BÁSICOS DE LA GESTIÓN ADMINISTRATIVA}

Se trata de tres aspectos esenciales que han quedado definidos e implantados en el Área de Medio Ambiente, no de forma rígida ni estática, sino en permanente desarrollo para su perfeccionamiento y adaptación a las nuevas circunstancias que inevitablemente sobrevienen en el tiempo. Estos elementos que, íntimamente engranados, propician una eficaz organización administrativa y un cumplimiento eficiente de las competencias asumidas, son los siguientes:

1. Una estructura orgánica.

2. Una tecnología y unos medios modernos.

3. Un sistema de gestión. 


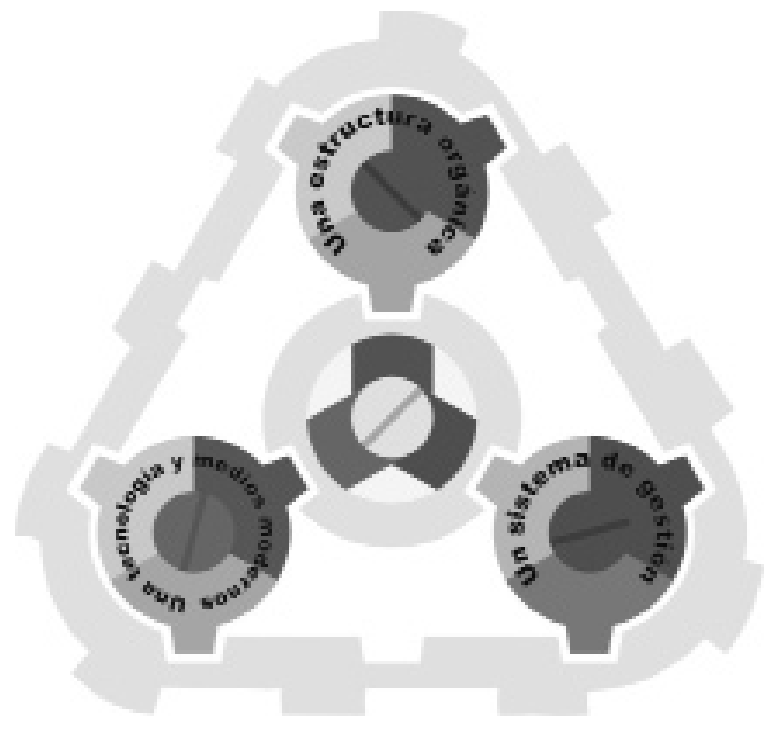

\subsection{Una estructura orgánica}

De acuerdo con el diagnóstico y objetivos reseñados en el apartado 3.2.1., el Área quedó compuesta por tres servicios, dos técnicos y uno administrativo:

- Servicio Técnico de Gestión Territorial Ambiental.

- Servicio Técnico Forestal.

- Servicio Administrativo de Medio Ambiente.

Estos servicios tienen bajo su jerarquía a las unidades administrativas que ejercen las distintas funciones del Área, siendo estas unidades de tres tipos, Territoriales, Insulares y Estructurales o Centrales. Su naturaleza y justificación quedan descritas convenientemente en el apartado 5.3.

Más tarde, una reestructuración orgánica del Cabildo Insular de Tenerife incorporó al Área un nuevo servicio, que ejerce las competencias de gestión insular de residuos: el Servicio Técnico de Sostenibilidad de Recursos y Energía.

\subsection{Una tecnología y unos medios modernos}

Obviamente, el cumplimiento adecuado de las competencias y objetivos de cual390 quier organización precisa de unos medios mínimos adecuados a los propósitos plan- 
teados. Y, por supuesto, éste es uno de los pilares de la planificación organizativa del Área, en el que el Cabildo de Tenerife ha realizado un esfuerzo económico muy considerable, completando debidamente los medios propios preexistentes en la Corporación y los incorporados con la transferencia de competencias desde la Administración Autonómica, que resultaban manifiestamente insuficientes.

El parque de vehículos, la maquinaria forestal, las instalaciones (múltiples infraestructuras repartidas por la geografía insular para la gestión administrativa, prevención de incendios, comunicaciones, producción de planta, recuperación de fauna, recreativas, acogida y pernocta de visitantes, educación ambiental, etc.) y otros numerosos medios técnicos, suponen una dotación notable y fundamental para el desempeño eficaz de las funciones. Pero, sin duda, en lo que a organización y eficiencia atañe, el medio más destacado son las TIC (tecnologías de la información y la comunicación), no sólo en lo que respecta al hardware (equipos informáticos, plotters, comunicaciones, agendas PDA con GPS para técnicos y agentes, etc.) sino muy especialmente a los aplicativos informáticos, los cuales se convierten en la herramienta imprescindible para poner en práctica todo el sistema organizativo que se está describiendo en el presente documento. El gestor de flujos documentales SIGMA, las aplicaciones informáticas de autorización de acampadas, licencias de caza, régimen sancionador, contratación, gestión de vehículos, almacén, señalización y amojonamiento, gestión de proyectos, gestión de personal, Plan Anual de Actividades, la Intranet corporativa, el sistema de información geográfica y su visor asociado, etc., son elementos que permiten el manejo fluido de muy distintos procesos que operan en el seno del Área. No disponer de ellos ralentizaría enormemente muchos de esos procesos e incluso imposibilitaría otros.

\subsection{Un sistema de gestión}

Es el tercer elemento, pero más crucial si cabe, que complementa necesariamente a los otros dos. Utilizando un símil informático, la estructura orgánica del Área (el equipo humano) equivaldría al usuario del ordenador, y los medios tecnológicos descritos en el anterior apartado, serían el hardware (el propio ordenador). Pero para que este ordenador pueda descifrar y procesar las operaciones que ordena el usuario y con ello permitir que funcionen correctamente los distintos programas informáticos instalados, precisa de un lenguaje, el denominado sistema operativo, que se trata de un software básico donde residen las claves y reglas para el funcionamiento del microprocesador del ordenador.

El sistema operativo del símil informático expuesto, se correspondería con el llamado sistema de gestión de la organización administrativa, unas "reglas del juego" que todas las unidades y su personal adscrito deben cumplir para trabajar coordinada y eficazmente, bajo unos mismos criterios, bajo un mismo ritmo, sin duplicidades, sin gastos superfluos y deparando un trato igual a todos los ciudadanos a los que se presta servicio, independientemente de la unidad del Área que los atienda o de la 
zona de la isla donde residan o ejerzan su actividad. En definitiva, si se requiere una definición de Sistema de Gestión, esta podría ser: Parte de una organización que incluye la estructura organizativa, los procesos, la planificación de las actividades, las responsabilidades, los procedimientos y los recursos para desarrollar, implantar, llevar a efecto, revisar y mantener al día la política de la organización.

Para diseñar un sistema de gestión es preciso dibujar el mapa de procesos de la organización, en nuestro caso, la secuencia de todas las relaciones causa-efecto que se producen en el seno del Área de Medio Ambiente. En la figura siguiente, aunque no resulte legible en su totalidad, se puede apreciar la estructura del mapa de procesos que se elaboró para el Área de Medio Ambiente.

\section{FIGURA 7}

Mapa de Procesos del Área de Medio Ambiente

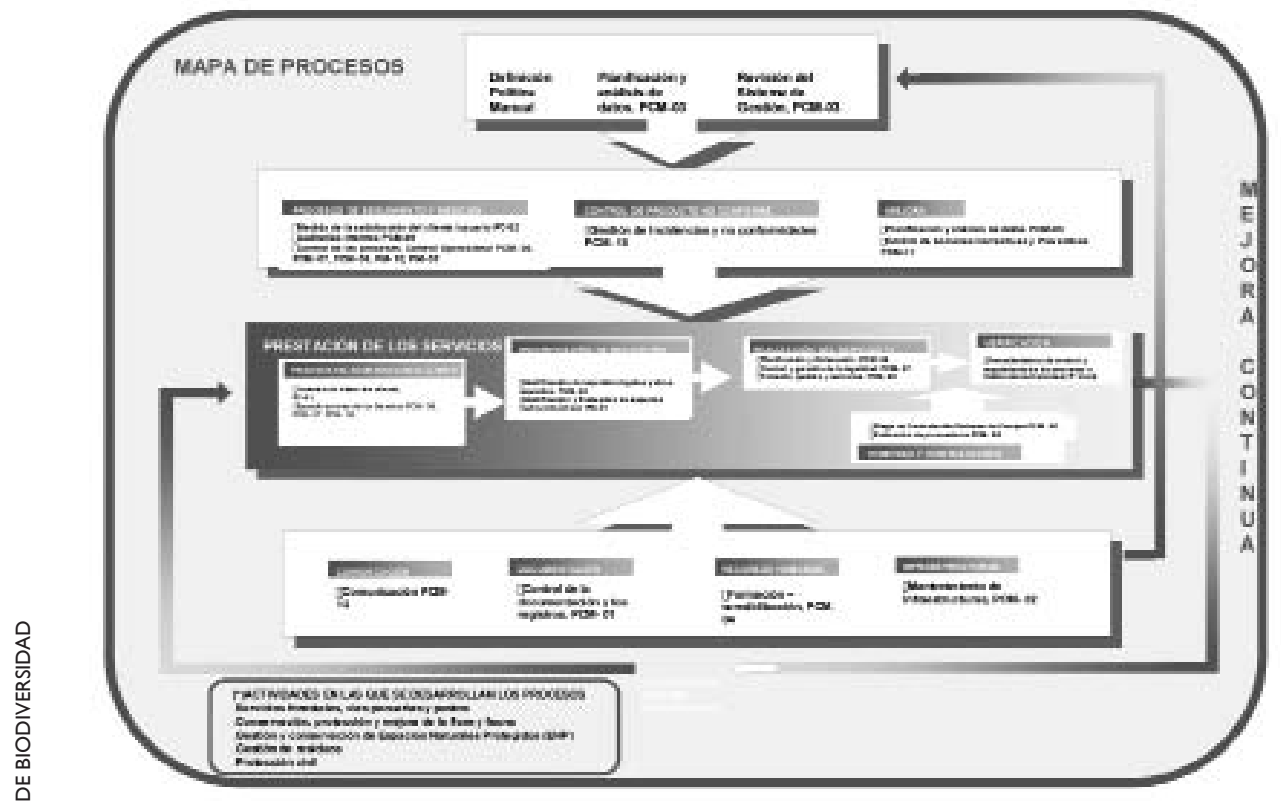

\subsubsection{Los procedimientos del sistema de gestión}

Con el mapa de procesos realizado, se deben tomar éstos uno por uno y tipificar sus pasos y etapas, de manera que se pueda diseñar el procedimiento que regulará cada proceso. Un procedimiento es una relación secuencial escrita de todas las acciones implicadas en un proceso y los actores que las realizan, a la que se pueden añadir

392 otras instancias y sistema de medición de los resultados, requisitos que deben ser 
observados por esos actores para que el sistema funcione correctamente y bajo unas mismas reglas en toda la organización.

La forma de elaborar un procedimiento puede ser variada. En nuestro caso, se ha vinculado con la teoría de sistemas, que se expuso en el apartado 3.1.1. Para ilustrar esto, sirva como ejemplo el procedimiento diseñado para regular uno de los principales procesos que operan en el sistema de gestión general del Área, que se encuadra dentro de las competencias de Policía y Garantía de la Legalidad a cargo de ésta: el denominado Sistema de Autorizaciones/Informes/Evaluación de Impacto, que comprende una serie de trámites administrativos establecidos por la normativa estructuralmente muy afines y que funcionan bajo una claves comunes entre sí. En realidad, más que un proceso, se puede considerar un macroproceso, pues engloba a varios procesos a la vez. El procedimiento queda redactado como sigue:

En consonancia con la teoría de sistemas, se define el macroproceso constituido por los procedimientos autorizatorios, de emisión de informes y evaluación de impacto, que actualmente son competencia del Área de Medio Ambiente, como un sistema abierto cuyas entradas serán las solicitudes que de estas tres materias se reciben por medio del el Registro General del Cabildo y de sus Oficinas Descentralizadas, los Registros Auxiliares del Área o mediante la valija interna de intercambio con el resto de Áreas de la Corporación (incluidas las solicitudes de unidades de la propia Área de Medio Ambiente), y cuyas salidas serán las notificaciones de los actos resolutorios de los referidos procedimientos.

Como elementos de dicho sistema se definen los siguientes:

1. Registro General del Cabildo de Tenerife, Registros Auxiliares y valija interna con el Cabildo.

2. Oficinas Comarcales del Área de Medio Ambiente.

3. Bases de datos informatizadas y archivo documental de procedimientos.

4. Unidades Territoriales (de Gestión de los Espacios Naturales Protegidos).

5. Unidades Insulares, es decir, aquéllas que tienen asignadas competencias de gestión y ordenación en materias específicas y concretas a escala insular, como Biodiversidad, Gestión Forestal, Educación Ambiental, Incendios, etc.

6. Unidad Funcional Impacto Ambiental y Seguimiento.

7. Órganos Resolutorios, siendo éstos los competentes para la firma de un acto administrativo resolutorio de cualquiera de los procedimientos objeto del presente protocolo (Consejero Insular de Medio Ambiente, Consejo de Gobierno Insular y Presidente o Pleno del Patronato Insular de Espacios Naturales Protegidos). 
8. Unidad Funcional Coordinación. Unidad definida como un centro de control de todo el sistema.

Como procesos del sistema, se definen las siguientes etapas:

1. Recepción de solicitudes de autorización, informe o declaración de impacto en la Unidad de Coordinación, procedentes de registro o valija interna.

2. Consulta por esta unidad en bases de datos, archivos o en las unidades administrativas correspondientes, de los antecedentes que concurren en cada caso (normativa de aplicación, expedientes anteriores relacionados, cédula ambiental, informe medioambiental, posibles procedimientos sancionadores previos, etc.).

3. Caracterización del caso concreto por la Unidad de Coordinación, estableciendo si precisa de un solo acto resolutorio, o bien deben concurrir varias de las figuras (autorización, informe o declaración de impacto).

4. Distribución a las unidades que han de elaborar la propuesta técnica para la resolución, incluyendo las instrucciones precisas y las conclusiones extraídas en el proceso de caracterización.

5. Elaboración de la propuesta técnica por las unidades correspondientes, incluyendo, si procede, la fase de consultas o comunicación a otras unidades afectadas. Cada tipo de procedimiento (autorización, informe de compatibilidad, informe de Patronato, informe tipificado en normas sectoriales o evaluación de impacto) dispondrá de una plantilla específica e independiente para cumplimentar su correspondiente propuesta técnica.

6. Envío de la propuesta técnica a la Unidad de Coordinación, quien le dará la forma de acto resolutorio mediante una nueva plantilla diseñada al efecto, la cual, como en el caso anterior, deberá ser específica e independiente para cada tipo de acto resolutorio.

7. Elevación del documento de acto resolutorio por La Unidad de Coordinación al órgano resolutorio correspondiente, previos los trámites de consulta e información pública o institucional a que hubiere lugar.

8. Firma del acto resolutorio, si procede, y reenvío a la Unidad de Coordinación.

9. Por parte de esta unidad, asiento en la base de datos correspondiente, notificación al solicitante o peticionario, archivo de expedientes y comunicación a las unidades administrativas afectadas, oficinas comarcales correspondientes y Registro de la Red Canaria de Espacios Naturales Protegidos, si procede. 
El procedimiento que regula el funcionamiento del macroproceso que hemos Ilamado "Sistema de Autorizaciones/Informes/Evaluación de Impacto" consiste, pues, en una serie de 9 pautas (procesos del sistema) que indican a cada uno de los actores (los 8 elementos del sistema) qué papel desempeñan y como deben actuar en cada etapa del proceso. Aunque no figura en el ejemplo indicado, este procedimiento debe ir acompañado de una ficha de proceso diseñada ad hoc, donde se contengan los plazos máximos de cumplimiento de cada etapa y unos indicadores cuantitativos (V. apartado 6.2.3.), que medirán periódicamente la buena aplicación del procedimiento (en especial, indicadores para conocer el cumplimiento de plazos, n. ${ }^{\circ}$ de incidencias, índice de satisfacción de los usuarios u otros que puedan ayudar a determinar la eficiencia del procedimiento por parte de cada unidad administrativa implicada o del Área en su conjunto).

\section{FIGURA 8}

\section{Ejemplo de pantalla de tareas del aplicativo SIGMA}

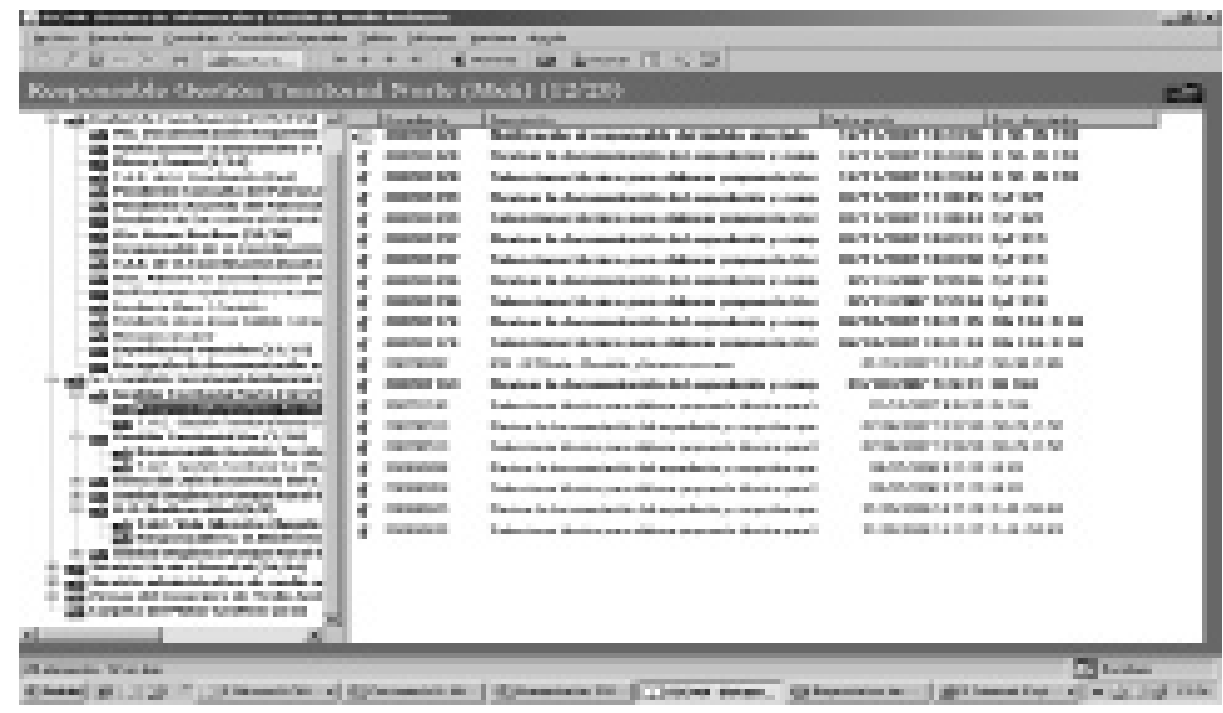

Numerosos procedimientos del Área de Medio Ambiente como éste han sido, además, traducidos en aplicaciones informáticas (muchas de ellas citadas ya en el apartado 4.2.) para ofrecer al personal encargado herramientas que agilicen su trabajo. En el caso del ejemplo anterior, el procedimiento escrito para el Sistema de Autorizaciones/Informes/Evaluación de Impacto ha servido para documentar el diseño del aplicativo informático SIGMA, sobre el que ya se ha comentado anteriormente, y que se ha convertido en una herramienta esencial de la gestión del Área. Se trata de un gestor de flujos de expedientes que permite aplicar mecanizadamente el procedimiento descrito, y que además, controla plazos y sirve para ofrecer datos estadísticos sobre cumplimientos de estos plazos y muchos otros aspectos. Con este aplicativo, el 
ordenador de cada persona recibe las tareas que a ésta le competen dentro un expediente sometido a un procedimiento dado (un expediente de autorización, informe o evaluación de impacto que se haya iniciado). La persona concreta despacha su tarea y ordena el paso a la siguiente etapa, ya en el ordenador de de otra persona. La unidad de control de todo el sistema procedimental es la Unidad de Coordinación, de la que parten y a la que regresan todos los flujos de expedientes.

En la figura 8 se muestra, como ejemplo, una pantalla correspondiente a las tareas que al abrir el aplicativo SIGMA en el ordenador, encuentra asignadas para sí uno de los técnicos gestores, en este caso, el Responsable de la Unidad de Gestión Territorial Norte (resaltado sobre fondo oscuro en el árbol de la parte izquierda de la pantalla). En la parte derecha de la pantalla se muestran todas las tareas que este responsable tiene pendientes en un momento dado al abrir el aplicativo, con descripción de la tarea, fecha de envío y expedientes asociados previos. Cada vez que se entra en una de estas tareas y se resuelve, el gestor de flujos la retira de esa columna y le da paso a la etapa siguiente, donde otro usuario encontrará en su carpeta de tareas la nueva correspondiente a él. Las tareas en negrita aún no han sido abiertas por el usuario. Las demás están ya en proceso.

Con este aplicativo, ya no ha de circular papel entre uno y otro funcionario implicado en el procedimiento, sino que todo el trabajo fluye por la red informática hasta su destino final. Se activan alarmas en el ordenador cuando se acerca el plazo de cumplimiento de la etapa de que se trate y deja registro de todos los trámites que comprende el procedimiento completo hasta que se resuelve definitivamente y sale del sistema. Esto se verá apoyado con el recurso de la firma electrónica que, en breve se espera implantar en el Área, pues toda la infraestructura tecnológica está ya preparada para esa implantación, en cumplimiento de la nueva Ley Estatal de Acceso Electrónico de los Ciudadanos a los Servicios Públicos.

\subsubsection{La organización documental del sistema de gestión}

Todo sistema de gestión debe poseer su plasmación en un sistema documental, que queda reflejado en la figura 9. En el nivel jerárquico superior se sitúa la política de calidad de la organización, un documento breve que suscribe el liderazgo de la organización -en este caso el Consejero del Área- y que constituye una "carta magna" donde constan los compromisos de funcionamiento, procedimiento y prestación de servicios a los clientes del Área (aquí, los ciudadanos particulares y personas jurídicas, privadas o públicas usuarias de los servicios). En segundo lugar se sitúa el manual de calidad, el documento donde se detalla el funcionamiento de las partes del sistema, las atribuciones de cada unidad responsable de procesos o la comunicación interna y externa, así como donde se enumeran todos los procedimientos y los sistemas de medida para el control. En el tercer nivel está todo el conjunto de procedimientos escritos (según lo explicado ya en el apartado anterior). Y, por último, en el cuarto 
mediciones de indicadores de control establecidas para esos procedimientos, y que quedarán como evidencias escritas del grado de bondad en el funcionamiento del sistema de gestión, con el fin de hacer un seguimiento de éste y definir las medidas correctivas a que hubiere lugar.

En el caso del Área de Medio Ambiente, el sistema de gestión se diseñó de forma integrada, tanto para la gestión de la calidad, como para la gestión ambiental de la organización, razón por la que en la figura 9 se habla de calidad y medio ambiente a la vez.

FIGURA 9

Organización jerárquica documental del sistema de gestión

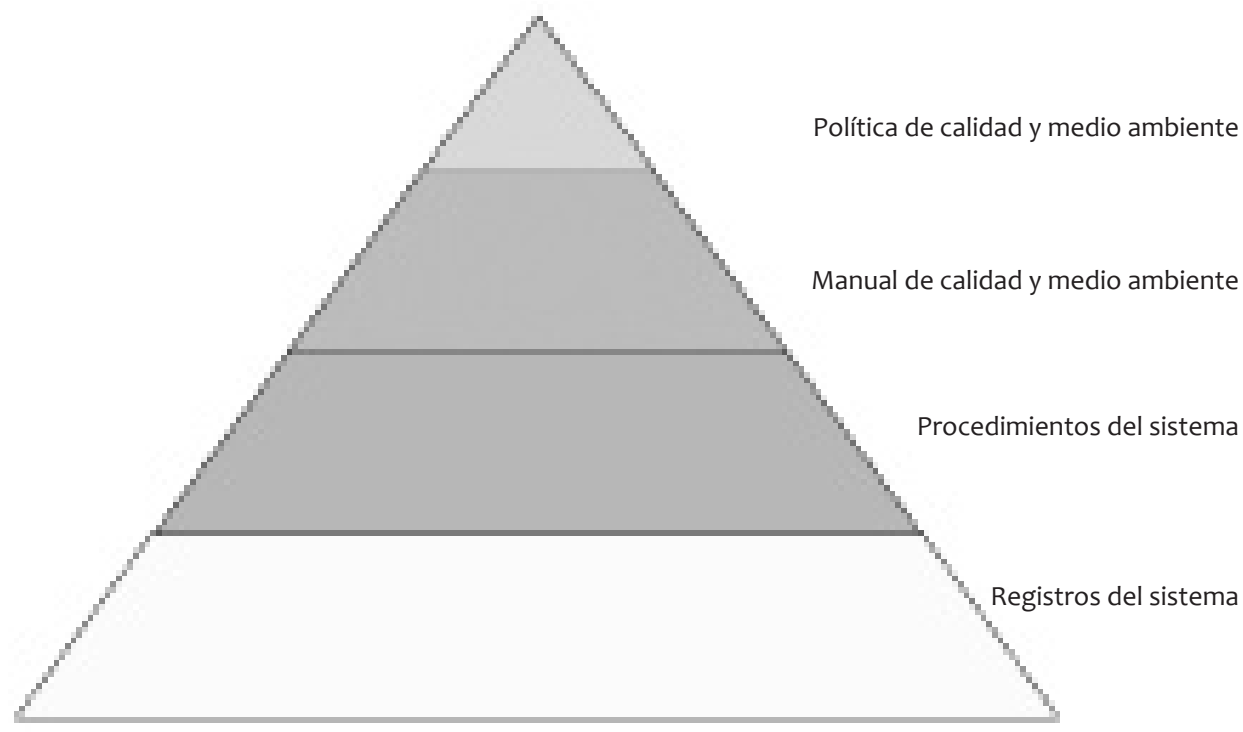

El sistema se certificó en 2006, en cuanto a gestión de la calidad, en la norma UNE-EN ISO 9001/2000, y en cuanto a gestión ambiental, en las normas UNE-EN ISO 14001/2004 y Reglamento EMAS de la Unión Europea. Sin embargo, siguiendo el principio de simplicidad, el sistema de gestión de la calidad se halla en revisión desde 2008, para conseguir una simplificación de los procedimientos, mientras se mantienen íntegramente en vigor el sistema de gestión ambiental.

\subsubsection{Principio de la mejora continua}

El sistema de gestión de una organización debería estar inspirado y regido por tres fases secuenciales e iterativas, que se representan en la figura10. Se trata de una adaptación del denominado Ciclo Deming, básico en los sistemas de gestión de la calidad. La repetición en el tiempo de este bucle conduce a lo que se denomina como mejora continua. Es decir, las acciones de la organización, en este caso el Área de Medio Ambiente, 
deben ser planificadas, ejecutadas de acuerdo con esa planificación, y luego evaluadas (medida de los resultados obtenidos, respecto a los objetivos planteados, mediante indicadores u otros medios). Conforme a los resultados de esa evaluación, la acción será replanificada o corregida, introduciendo las mejoras oportunas.

\section{FIGURA 10}

La mejora continua en los sistemas de gestión de las organizaciones

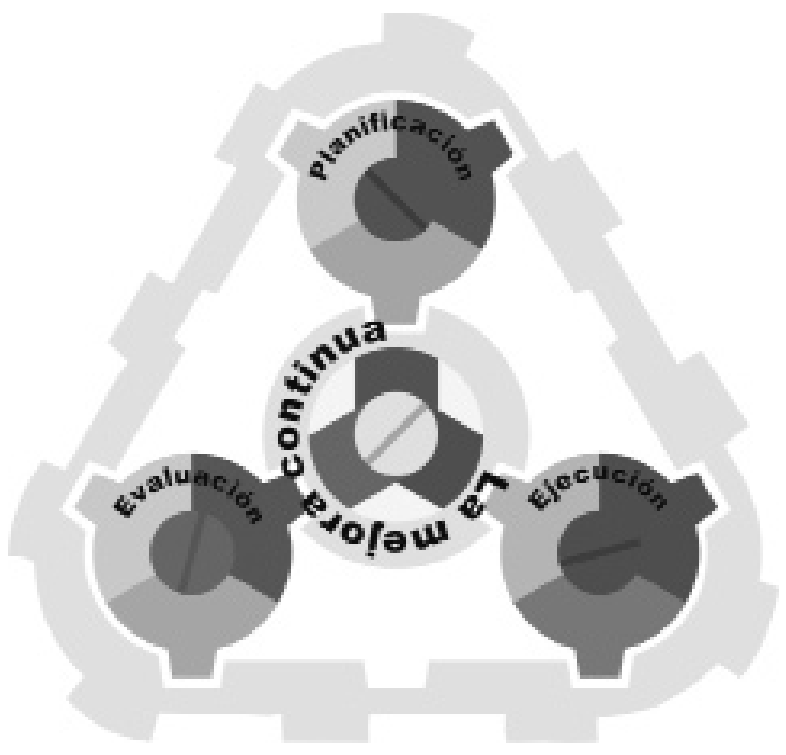

Los procedimientos del sistema descritos en apartados anteriores, son una forma de planificación de las acciones (procesos) que lleva a cabo de forma continua el Área de Medio Ambiente. Es el caso del ya referido procedimiento del "Sistema de Autorizaciones/Informes/Evaluación de Impacto", al que se añaden otros para el resto de procesos, tan variados como: contratación y compras, gestión de proyectos, formación del personal, mantenimiento preventivo de infraestructuras, control de consumos de agua y electricidad, gestión de los residuos del Área, emergencias, etc., e incluso la propia planificación.

De acuerdo con uno de éstos (el procedimiento de gestión de proyectos), cada proyecto acometido en el Área, sea de una obra, de una campaña de concienciación ambiental o de un estudio, debe disponer de una ficha de proceso, con una parte destinada a los objetivos, otra para las acciones y su temporalización (fases e hitos), un apartado presupuestario y, por último, la parte de evaluación, con los indicadores, cualitativos o cuantitativos y medidas a tomar para la corrección, si procede.

Por último, es evidente que en la vida administrativa, el “día a día” provoca situa398 ciones nuevas a las que se ha de responder mediante las acciones oportunas, con lo 
que estas acciones no han sido planificadas o no disponen para su realización de un procedimiento preestablecido, pero, en la medida de lo posible, se debe asegurar que exista la mayor parte de veces una planificación y una previsión que dicten cómo se ha de responder a la incidencia ocurrida. En definitiva, lo que se pretende es dejar en la organización lo menos posible a la improvisación, ya que se trata de una fuente de complejidad y caos que debe ser controlada al máximo nivel, siempre que sea racional y rentable humana y económicamente. La experiencia de los años, el tener que afrontar nuevas situaciones, debe producir como efecto que la organización ponga a punto nuevos procedimientos que vayan completando la lista inicial de éstos.

\section{LA GESTIÓN: ORGANIZACIÓN Y FUNCIONES DEL ÁREA}

Terminado ya de explicar el sistema de gestión, es decir, las reglas y principios que se aplican a todas las actividades que componen la vida del Área de Medio Ambiente, se pasará a continuación a describir propiamente esas actividades y la forma en que se ha estructurado el Área para realizarlas, fruto todo ello del proceso organizativo que fue descrito en el apartado 3.2. Tres preguntas se pueden formular para conocer la estructura y el funcionamiento del Área de Medio Ambiente:

¿QUÉ hacemos?, ¿CÓMO lo hacemos? Y ¿QUIÉN lo hace?

(V. la respuesta a estas preguntas en la figura11 y su desarrollo en los siguientes epígrafes).

\section{FIGURA 11}

Esquema de la organización funcional del Área de Medio Ambiente

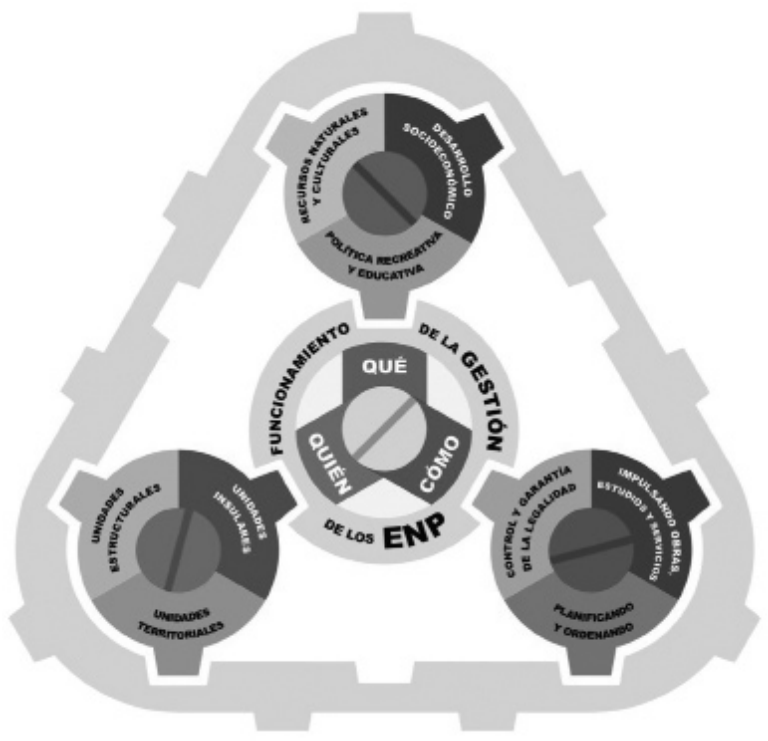




\subsection{Qué: Competencias del Área de Medio Ambiente}

Estas competencias están simbolizadas por la rueda dentada superior del esquema de la figura11, representando que las funciones de toda el Área de Medio Ambiente, referidas en la introducción del Capítulo 3, pueden ser agrupadas por afinidad en tres conjuntos que se describen en los tres apartados que figuran a continuación:

\subsubsection{Conservación, manejo y aprovechamiento de recursos naturales y culturales}

Incluye todas las competencias en gestión de espacios naturales protegidos, gestión forestal, conservación de la biodiversidad y uso de ésta (investigación, seguimiento, control de poblaciones cinegéticas, etc.), prevención y extinción de incendios, aprovechamientos (madera, pinocha, rama verde, apicultura, etc.), protección del patrimonio histórico de los espacios naturales, etc., así como técnicas y procedimientos jurídico-administrativos dentro de la competencia "protección del medio ambiente". Por último, se ha venido a añadir la nueva competencia de gestión de residuos, que también es gestión de recursos, los cuales dan precisamente nombre al Servicio Técnico de Sostenibilidad de Recursos y Energía.

\subsubsection{Políticas recreativa y educativa de la naturaleza}

Incluye, por un lado, todas las competencias en promoción y regulación del uso público y la visita de la naturaleza y los espacios naturales, ya sea por razones de recreo, deporte, laborales o culturales, y siempre que no impliquen ninguna actividad extractiva. Dar ocasión al disfrute de la naturaleza -un derecho constitucional en España- en condiciones de calidad y seguridad, permite que la población aprenda a querer y respetar el patrimonio natural, al acceder a experiencias agradables brindadas por éste. Ello constituye, por su parte, una actividad ampliamente demandada por la población, por lo que debe estar sometida a regulación y atención permanente de la Administración.

Por otro lado, este epígrafe incluye todas las competencias en promoción y desarrollo de la interpretación, la educación y la comunicación ambientales, muy asociadas al uso de la naturaleza y que son piezas clave en el acercamiento del valor del patrimonio natural a la ciudadanía, creando los canales adecuados para el contacto con las personas y proporcionándoles no sólo conocimientos y capacitación para desarrollar una conducta favorable hacia el medio, sino información de las acciones que desarrolla la Administración con sus impuestos.

\subsubsection{Desarrollo socioeconómico de las poblaciones}

Crucial es, como ya se introdujo en el Capítulo 1 del presente trabajo, vincular es400 trechamente la economía, la vida social y la participación ciudadana a la política ambien- 
tal, de forma que se consiga una acción integrada en los campos ambiental, económico y social. El Área de Medio Ambiente desarrolla varias líneas de trabajo, unas relacionadas directamente con la mejora de las condiciones de vida de la población residente o dependiente de espacios naturales protegidos, y otras con los agentes económicos, buscando la armonización de los objetivos de progreso de éstos con los objetivos de protección del medio ambiente. Son importantes los proyectos realizados desde 2004 en colaboración con otras entidades y empresas para la información y formación de empresarios en materias ambientales que les afectan, así como para la promoción de nichos de negocio ambiental rentables entre inversores y emprendedores.

Por último, destaca de forma muy importante la línea de trabajo relacionada con la participación ciudadana y el fomento del capital social, un factor indisociable del denominado desarrollo sostenible de la civilización. En esta línea fue creada en 2004 la Oficina de la Participación y el Voluntariado Ambientales, de acuerdo con lo establecido por Plan de Acción del Voluntariado Ambiental de Tenerife, la cual ha servido en estos años de vía para canalizar las inquietudes de numerosos tinerfeños por el medio ambiente y para abordar otros proyectos como el voluntariado internacional y la responsabilidad social corporativa de las empresas.

\subsection{Cómo: Modos de intervención de la Administración para cumplir sus competencias}

La Administración está facultada para ejercer sus funciones mediante tres tipos principales de intervención, descritas a continuación para el caso del Área de Medio Ambiente.

\subsubsection{Planificación y ordenación}

Cualquiera de las materias que se describieron en el apartado 5.1. y que constituyen las competencias del Área de Medio Ambiente, deben estar sometidas a una planificación, siguiendo varios de los principios ya expresados a lo largo de este documento. Ya se ha enunciado también en el apartado 4.3.3. la importancia para la mejora continua de que las acciones se hallen planificadas, evitando la improvisación en la medida de lo posible.

Salvo en alguna cuestión concreta como los espacios naturales protegidos, en que la planificación está reservada a la Administración de la Comunidad Autónoma, el Área de Medio Ambiente está facultada para planificar las materias a su cargo e incluso tiene otorgada la potestad reglamentaria externa para dictar disposiciones a cumplir por la ciudadanía en la regulación de los usos ambientales. Aparte de ello, el Área participa en la elaboración de otros planes a cargo de diferentes instancias administrativas, así como informa otros muchos en que no participa, pero que afectan a las competencias que tiene asumidas. 
El Área de Medio Ambiente ha elaborado y desarrolla variados planes en materia de biodiversidad, uso público, caza, educación ambiental, voluntariado, desarrollo de parques rurales, etc.

\subsubsection{Policía y garantía de la legalidad}

La segunda forma de intervención de la Administración para cumplir las obligaciones derivadas de sus competencias se ha plasmado dentro el Área en el ya comentado Sistema de Autorizaciones/Informes/Declaración de Impacto. Existen más de 30 procedimientos autorizatorios establecidos por la normativa, ya sean en competencias sobre recursos naturales (autorizaciones para usos o estudios de flora y fauna, licencias de caza, aprovechamientos en montes, quema de rastrojos, etc.), sobre política recreativa (autorizaciones de acampadas, de circulación de vehículos por pistas de espacios naturales, homologación de senderos, etc.) o sobre desarrollo socioeconómico (autorizaciones, informes o evaluaciones de impacto sobre proyectos o actividades a realizar en espacios naturales, ya sean agrarias, industriales o de servicios).

A estos procedimientos se unen como competencia del Área los sancionadores por infracciones tipificadas en distintas leyes, como infracciones de caza, afección a flora y fauna, circulación por pistas, quemas ilegales o acampadas ilegales.

\subsubsection{Fomento, gestión y servicios}

Se trata de las intervenciones de carácter material y creativo a cargo de la Administración, es decir, todo lo relacionado con la ejecución de obras, estudios, servicios, mantenimiento, limpieza, etc., que se determinan como necesarios en los tres campos competenciales del Área: conservación, manejo o aprovechamiento de recursos (construcción y mantenimiento del Centro de Recuperación de Fauna, Jaulón de cría de perdices, viveros de plantas autóctonas, obras de corrección hidrológica, campañas de prevención y extinción de incendios, estudios sobre ecosistemas en peligro y un largo etcétera); políticas recreativa y educativa (construcción y mantenimiento de áreas recreativas, campamentos, centros de visitantes, aulas en la naturaleza, camping, así como estudios de capacidad de acogida, planificación y construcción de redes de senderos, campañas de educación ambiental o servicios de gestión de las visitas en determinados espacios, etc.); o, en tercer lugar, en el desarrollo socioeconómico (construcción del Mercadillo de Productos Locales de Anaga, apertura o acondicionamiento de pistas agrícolas en distintos espacios, equipamientos y dotaciones en núcleos rurales, realización del Banco de Ideas de Negocios Ambientales, etc.).

\subsection{Quién: Estructura orgánica del Área de Medio Ambiente}

Se trata de la organización del quipo humano que lleva a cabo el trabajo del Área. 402 En este apartado se describirá la estructura orgánica ya citada en el apartado 4.1.1., 
que fue creada mediante el proceso descrito en los epígrafes 3.2.2. y 3.2.3. del presente trabajo.

Existen en el Área tres servicios técnicos y uno administrativo, cada uno de los cuales tiene adscritas unidades orgánicas y funcionales, que se agrupan en tres clases, Unidades Territoriales, Unidades Insulares y Unidades Estructurales o Centrales, de manera que en su conjunto racionalizan el cumplimiento de la gestión a cargo del Área de Medio Ambiente, manteniendo siempre los criterios de economía administrativa y ahorro de recursos presupuestarios, según se explica a continuación.

\subsubsection{Unidades Territoriales}

Debido al extenso territorio de la isla, y tanto con fines organizativos y de eficacia, como de proximidad al ciudadano, se decidió como solución adecuada zonificar la isla en sectores o zonas, cada una de las cuales alberga tanto espacios naturales como territorio no protegido. Se designó para cada zona un equipo humano (personal técnico y administrativo, monitores e informadores, agentes y vigilantes de medio ambiente, así como operarios y capataces de cuadrillas para el trabajo de campo) que atiende las competencias de:

1. Vigilancia e inspección del medio natural, así como control y seguimiento de actividades autorizadas. Son funciones realizadas por agentes de medio ambiente y vigilantes de espacios naturales protegidos.

2. Tratamientos selvícolas, así como obras, mantenimiento y limpieza, tanto en infraestructuras como en el resto del territorio.

3. Promoción del desarrollo económico y la mejora de la calidad de vida de las poblaciones humanas de espacios naturales protegidos.

4. Uso público, interpretación, información y concienciación ambientales, en coordinación con las unidades centrales encargadas de estas materias.

5. Gestión administrativa y atención al público en oficinas comarcales.

6. Propuesta técnica de autorizaciones e informes preceptivos.

7. Actuar como oficina de gestión de los espacios naturales protegidos existentes en la zona correspondiente (existe en Tenerife una red de 43 áreas protegidas, a la que se suman los espacios de la Red Natura 2000 de la UE, muchos coincidentes con los 43 anteriores, pero con 17 Lugares de Importancia Comunitaria, varios de ámbito marino, y 2 ZEPA que suponen territorio protegido adicional al de la Red). 
Las unidades encargadas en su zona respectiva de ejercer estas funciones son siete y se representan en la figura12, perteneciendo las tres denominadas como Zonas Este, Centro y Oeste, al Servicio Técnico Forestal y las cuatro restantes al Servicio Técnico de Gestión Territorial Ambiental:

\section{FIGURA 12}

\section{Distribución de las Unidades Territoriales}

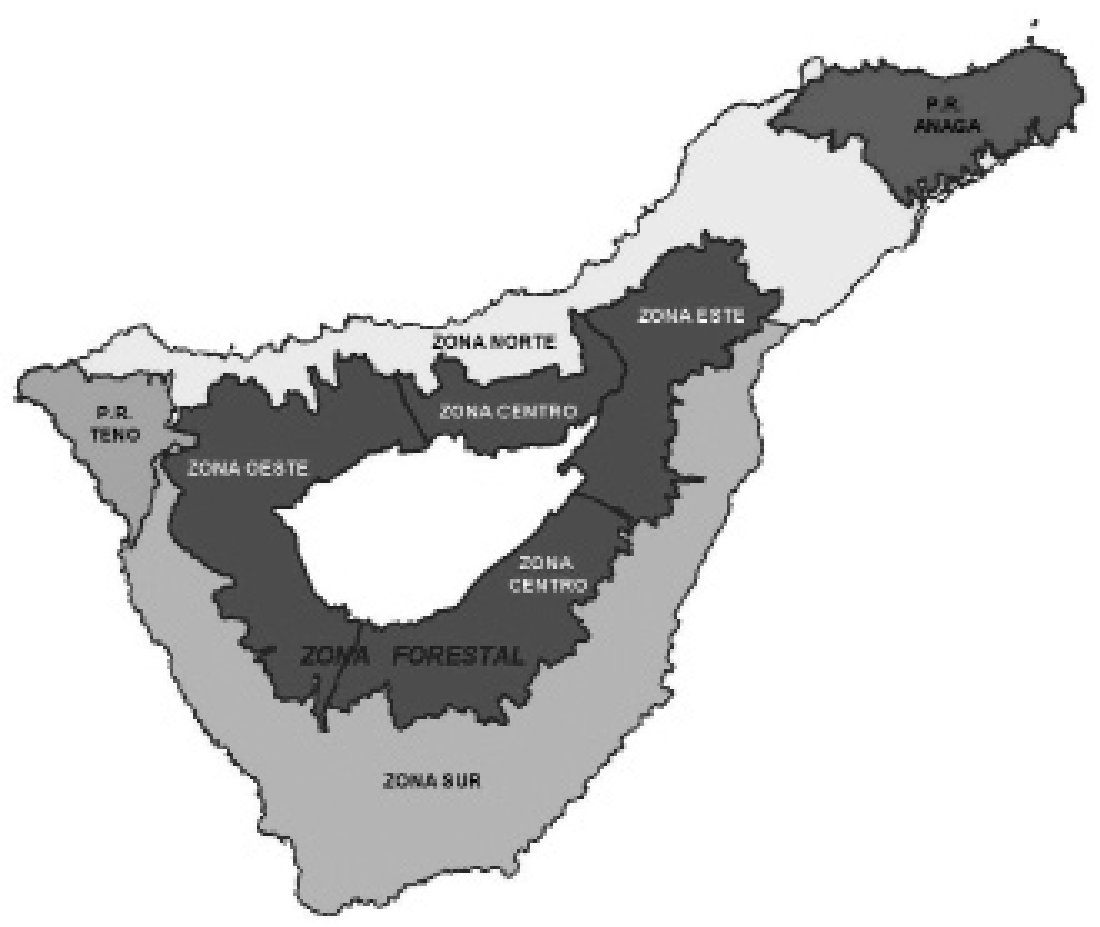

\subsubsection{Unidades Insulares}

Determinadas materias no se prestan a la gestión territorializada anterior porque no serían eficaces, fragmentarían los esfuerzos y no dispondrían de la debida coordinación y, por ello, son ejercidas en todo el ámbito insular bajo un mando único. Un ejemplo es la prevención y extinción de incendios forestales, capítulo de gran trascendencia en cuanto a la seguridad de las personas y la conservación, que necesita alta concentración de esfuerzos, en momentos muy concretos y en puntos indeterminados de la geografía, y que debe desplegar un sistema muy organizado y coordinado, precisando un plantel humano, material y vehículos integrados en un solo 404 dos para este cometido. 
Las unidades que ostentan competencias insulares, coordinando esas materias para toda la isla (aunque pueden contar con la colaboración de las unidades territoriales), son las siguientes:

- Biodiversidad y Caza.

- Incendios.

- Gestión forestal (infraestructuras e hidrología, aprovechamientos, repoblaciones).

- Educación Ambiental y Proyección Social.

— Oficina de la Participación y el Voluntariado Ambientales.

— Servicio de Sostenibilidad de Recursos y Energía.

\subsubsection{Unidades estructurales o centrales}

El tercer grupo de unidades es el encargado de dar coherencia global al conjunto del sistema, actuando como apoyo a todas las unidades del Área, ya sean Territoriales, Insulares o las propias Estructurales. Gestionan procesos comunes y sirven de puntos de coordinación y control del sistema. Algunas, como la Unidad de Medios Mecánicos o la de Aplicaciones Informáticas y Sistema de Información Geográfica, funcionan también como herramientas del sistema, de las que se valen otras unidades para su desempeño propio.

Para llegar a determinar las unidades estructurales y sus funciones, se siguieron los razonamientos que se exponen a continuación, de acuerdo con las Teorías de Sistemas y Control de Flujos: en consonancia con lo expuesto en el apartado 3.2., si se quiere controlar un sistema complejo para coordinar y optimizar los recursos empleados así como para disminuir los tiempos invertidos en los procesos, y mejorar con ello las salidas del sistema, se ha de encontrar, de entre todos los elementos de éste, cuáles tienen mayor influencia sobre los demás elementos y sus procesos asociados, y ejercer el control principal desde esos elementos clave.

El máximo elemento clave de este sistema es el liderazgo, pero en su nivel político es variable en el tiempo y en su nivel técnico está conformado por los jefes de servicio, los cuales ejercen sus funciones propias con distintas formas, intensidad y criterios. Por lo tanto, deberá existir una estructura adicional que permita atenuar y regularizar estos condicionantes para conseguir un alineamiento estratégico, homogéneo y eficiente del trabajo de las distintas unidades del Área.

Hay dos tipos de control: coercitivo, que fiscaliza y rechaza los expedientes que no cumplen los requisitos mínimos, manteniendo la disciplina interna, y regulador, 
que desarrolla la planificación de forma coordinada entre las distintas unidades, regula y controla los flujos de procedimiento y sus plazos, mantiene la uniformidad de criterio jurídico, así como mide los indicadores básicos para conocer la evolución del sistema y sus desviaciones de los objetivos y compromisos marcados.

De acuerdo con lo expuesto, las Unidades Estructurales o Centrales quedan como sigue, especificándose cuáles son unidades de control del sistema y de qué tipo:

Unidades administrativas:

- Contratación (ejerce control administrativo coercitivo).

- Disciplina Ambiental.

Unidades técnicas:

- Impacto Ambiental y Seguimiento (ejerce control técnico coercitivo).

- Planificación y Gestión Presupuestaria (ejerce control técnico regulador).

- Coordinación (ejerce control técnico y administrativo, coercitivo y regulador).

- Aplicaciones Informáticas y Sistema de Información Geográfica.

- Medios Mecánicos.

Las Unidades de Coordinación, Planificación y Gestión Presupuestaria, Impacto Ambiental y Seguimiento y Aplicaciones Informáticas y Sistema de Información Geográfica, son unidades de carácter técnico que, además, deben mantener una coordinación muy especial entre ellas para actuar de forma homogénea y con unidad de criterios ante toda el Área, por lo que se acordó adscribirlas como unidades funcionales a una nueva unidad orgánica denominada Planificación, Coordinación Técnica y Control de Gestión.

La unidad de planificación, coordinación y control es una figura que debe existir en cualquier organización. En una entidad pequeña, esta unidad puede constar de una sola persona; en un departamento grande pueden ser varios los componentes, a ser posible, de carácter multidisciplinar, combinando técnicos en distintas materias, con juristas y economistas. Esta unidad proporciona un punto focal de cohesión y coordinación de criterios en la planificación y las actuaciones de la organización (tanto en el nivel técnico como en el jurídico) y se encarga de los procesos de diseño y evaluación de la calidad en la gestión, así como de proponer las medidas correctivas necesarias; propicia también la evitación de duplicidades, la unidad de imagen, la regulación y control de los flujos de procedimiento, la eficacia y la eficiencia presupuestarias, la coordinación con otros departamentos de los sectores público y privado, 406 etc., aspectos todos de los que tantas veces se halla falta la Administración. 


\section{EL SEGUIMIENTO Y LA EVALUACIÓN}

Habiéndose abordado hasta aquí los dos primeros elementos del ciclo de la mejora continua, la planificación y la gestión (V. apartado 4.3.3.), corresponde ahora tratar el tercero de los pasos del ciclo, la evaluación, describiendo cómo se ha enfocado hasta la fecha en el Área de Medio Ambiente.

\subsection{Necesidad del seguimiento y la evaluación}

Ambos elementos son indispensables para confirmar si la gestión se ha ajustado a lo previsto en la planificación y también para detectar y cuantificar incidencias, imponderables, desviaciones o variables crípticas que influyen decisivamente en los resultados del proyecto en el que trabajamos. Ello permite estudiar y aplicar las medidas correctivas adecuadas sobre el proyecto o medidas preventivas en otros similares que puedan acometerse después.

Con la evaluación podemos encontrar dónde están los problemas de un flujo, sus cuellos de botella, sus variables clave, sus carencias, obstáculos, velocidad de las cosas, ineficiencia de alguno de los pasos o sus responsables y cuantificar con certeza la falta de recursos real en un paso concreto. Igualmente, podremos encontrar vías objetivas para valorar la productividad de las unidades administrativas de la organización y sus empleados, así como de los proveedores y contratistas. Y, por último, la evaluación permite trabajar de cerca con los ciudadanos y sondear e interactuar con ellos en varios terrenos, como satisfacción, opinión o nivel de participación.

\subsection{El sistema de seguimiento y evaluación del Área de Medio Ambiente}

El seguimiento y evaluación de la eficacia en la gestión del Área de Medio Ambiente es un proceso en tres niveles que se halla actualmente en desarrollo, existiendo un modelo piloto que se ha ido probando y midiendo desde 2006. Un resumen de este proyecto fue publicado en una edición de UICN y otros varios organismos, consistente en una revisión de los trabajos de evaluación de la eficacia en la gestión de espacios naturales protegidos a lo largo de los cinco continentes (García Díaz, 2008).

\subsubsection{Nivel 1: Seguimiento de los planes ejecutados por el Área (incluyendo los planes de espacios naturales protegidos)}

En general, con este seguimiento se pretende revisar el grado de cumplimiento de las acciones propuestas por los planes cuya ejecución está encomendada al Área, ya sean planes de rango insular, ya de un ámbito más reducido, como el de un espacio natural protegido, o bien de una materia sin incidencia territorial. En concreto, los objetivos que se persiguen son: 
1. Conocer qué acciones del plan se están llevando a cabo.

2. De las que se están acometiendo, comprobar si se hacen en plazo.

3. De las mismas, comprobar si se hace con el presupuesto planificado inicialmente.

4. Evaluar si han surgido dificultades en la aplicación del plan y enumerarlas.

5. Diseñar medidas para corregir esas dificultades.

Para efectuar el seguimiento se diseñó un modelo de ficha de datos, cumplimentándose una por cada acción de las establecidas por el plan. Cada ficha consta de dos cuerpos: datos fijos, descriptivos de la actuación planificada, y seguimiento propiamente de la acción.

\subsubsection{Nivel 2: Seguimiento del Plan Anual de Actividades}

Una de las innovaciones incorporadas en 2001 sobre la estructura orgánica y funciones del Área de Medio Ambiente fue la introducción de la figura denominada Plan Anual de Actividades, que contiene todas las actividades (proyectos, acciones, adquisiciones) que las unidades del Área se plantean realizar anualmente. Este plan ha de quedar configurado a fines del año anterior al que se programa, cuando ya se han aprobado los Presupuestos del Cabildo Insular. Las actividades se encuadran en 10 líneas de actuación, según materias (biodiversidad, servicios forestales, uso público, etc). Para cada una de esas actividades se hace constar en el plan su título, breve descripción, presupuesto asignado, partida presupuestaria, municipio y espacio natural protegido implicado, si procede. Una aplicación informática permite a todas las unidades del Área sentar sus actividades previstas, que luego figurarán inscritas automáticamente en el plan definitivo. Otra aplicación sirve a la Unidad de Planificación y Gestión Presupuestaria para realizar el seguimiento del cumplimiento del mismo.

Los objetivos del seguimiento del Plan Anual de Actividades son:

1. Conocer qué proyectos del Plan se han llevado a cabo y su grado de cumplimiento.

2. Distinguir las actividades del Plan que se hallan establecidas en planes de espacios naturales protegidos, en otros planes, o no contempladas en planes (con ello, al término del ejercicio planificado se podrá comprobar qué parte del presupuesto se gastó de forma improvisada, fuera de esta planificación).

3. Conocer cada año la distribución real del presupuesto, por servicios, por materias, por espacios naturales y por capítulos presupuestarios.

408 4. Medir la eficacia y la eficiencia del gasto presupuestario anual. 
Cada proyecto contenido en el Plan Anual se somete a análisis, de acuerdo con el siguiente cuadro:

\begin{tabular}{|l|c|c|c|c|c|}
\hline PROYECTO & $\begin{array}{c}\text { Estado } \\
\text { actual }\end{array}$ & $\begin{array}{c}\text { Fecha } \\
\text { de inicio }\end{array}$ & Fecha de fin & $\begin{array}{c}\text { Coste } \\
\text { planificado }\end{array}$ & $\begin{array}{c}\text { Coste } \\
\text { definitivo }\end{array}$ \\
\hline & & & & & \\
\hline
\end{tabular}

Con estos datos de cada proyecto, se elaboran informes globales que responden a los cuatro objetivos antes referidos.

\subsubsection{Nivel 3: Criterios de calidad (eficiencia)}

El tercer nivel de seguimiento pretende medir periódicamente la eficiencia en los procesos concretos del Área, detectar anomalías y corregirlas. Se basa en los resultados de la medición de los indicadores correspondientes a los distintos procedimientos del sistema (registros del sistema), según se describió en los apartados 4.3.2. y 4.3.3.

Como ya se ha dicho, cada unidad administrativa diseñó entre 2003 y 2006 sus propios indicadores, cuya medición periódica da cuenta de distintas variables significativas para la gestión y de la bondad en el cumplimiento de los objetivos y procesos principales operantes en la unidad de que se trate. Las características de estos indicadores deben incluir:

- Ser auténticamente útiles para controlar las variables clave de los procesos de la unidad (no se puede emplear tiempo en medir datos brutos que no hablen de aspectos clave del funcionamiento).

- Ser de fácil medida (los indicadores deben ser preferentemente cuantitativos para evitar en lo posible la subjetividad y la indeterminación, pero pueden ser cualitativos, si la magnitud que se analiza no se presta a ser cuantificada, como p. ej, opinión de los ciudadanos).

- Ser precisos y representativos de la magnitud a medir.

- Admitir la delimitación de un rango de aceptación en los valores que mide el indicador.

Por lo tanto, pueden existir indicadores cualitativos útiles, pero siempre será más fácil y preciso introducir mejoras concretas en algo que se puede medir, estableciendo unos rangos o márgenes de aceptación. La estructura de un indicador cuantitativo del Área es la siguiente: 


\begin{tabular}{|c|c|c|c|c|c|c|c|}
\hline \multirow[b]{2}{*}{$\begin{array}{l}\text { Indicador } \\
\text { (nombre) }\end{array}$} & \multirow[b]{2}{*}{$\begin{array}{c}\text { Sistema } \\
\text { de control }\end{array}$} & \multirow[b]{2}{*}{$\begin{array}{l}\text { Frecuencia } \\
\text { de medida }\end{array}$} & \multirow[b]{2}{*}{ Histórico } & \multicolumn{2}{|c|}{ Rango } & \multirow[b]{2}{*}{$\begin{array}{l}\text { Responsable } \\
\text { de la medida }\end{array}$} & \multirow{2}{*}{$\begin{array}{l}\text { Valor actual } \\
\text { (p. ej. } \\
\text { diciembre } \\
\text { 2009) }\end{array}$} \\
\hline & & & & $\begin{array}{l}\text { Valor } \\
\text { Min. }\end{array}$ & $\begin{array}{l}\text { Valor } \\
\text { Max. }\end{array}$ & & \\
\hline & & & & & & & \\
\hline
\end{tabular}

Ejemplos de indicadores:

1. Indicadores de Planificación y Ordenación:

— Tiempo medio de emisión de informes sobre planes externos.

- Presupuesto dedicado a uso público/presupuesto total de la unidad.

— Fondos invertidos en conservación/hectárea/año.

- Puestos de trabajo creados en el espacio protegido/año.

2. Indicadores de Policía y Garantía de la Legalidad:

— Tiempo medio de resolución en declaraciones de impacto.

— Número de resoluciones de autorizaciones de flora y fauna fuera de plazo.

— Número de expedientes urgentes/total de expedientes tramitados/mes.

— Tiempo medio de la fase de caracterización de expedientes.

- Número de quejas y reclamaciones por asuntos de caza/año.

3. Indicadores de fomento, gestión y servicios:

— Porcentaje de marras en repoblaciones forestales.

— Número de perdices cinegéticas liberadas al medio después de la cría.

— Tiempo medio de llegada a conatos de incendio.

- Coste medio de mantenimiento (preventivo y correctivo)/vehículo del parque móvil.

— Número de usuarios de áreas recreativas/año.

Una fase fundamental del seguimiento con indicadores es la interpretación de los resultados, que debe quedar por escrito en cada medición periódica del indicador.

410 Cualquier resultado anómalo en la medida (valores fuera del rango de aceptación) 
debe llevarnos a buscar su causa, pensando, además, que ésta no es siempre evidente y puede requerir cierto esfuerzo.

\subsubsection{Nuevos campos de trabajo en materia de seguimiento}

Existen otros tipos de seguimiento dentro del Área, no relativos ya a la eficacia y la eficiencia de la organización, sino al estado de diversas variables, como seguimientos ecológicos (p.ej de poblaciones vegetales en peligro, de gatos asilvestrados, etc.), administrativos (cumplimiento por los particulares de los condicionantes establecidos en autorizaciones y declaraciones de impacto), etc., pero siguen existiendo campos aún no abordados que invitan a ampliar el seguimiento realizado por el Área, profundizando en el análisis de la situación de los recursos naturales y culturales, y de la situación socioeconómica de las poblaciones ligadas a éstos, pero sobre todo, es preciso interactuar con la ciudadanía para que el seguimiento cobre su total dimensión.

En concreto, el seguimiento de la eficacia en la gestión debe mejorarse y extenderse, en especial a las fases de la gestión denominadas outputs y outcomes (resultados concretos y metas alcanzadas), incorporando un aspecto fundamental, que es el seguimiento en la población de los resultados que hemos obtenido. Es deber de las Administraciones trasladar a la sociedad la gestión realizada, sondear su opinión y establecer canales de comunicación para la participación directa de los ciudadanos en esa gestión, como se expresó ya en el apartado 1 del presente trabajo. Éste es, pues, un reto primordial que trata ahora de afrontar el Área de Medio Ambiente del Cabildo Insular de Tenerife.

\section{BIBLIOGRAFÍA}

Daly, H. E. 2005. La Economía en un Mundo Repleto. Investigación y Ciencia 350: 5865.

García Díaz, V. 2008. Tenerife, Spain. En: Leverington, F., Hockings, M., Pavese, H. Lemos Costa, K. y Courrau, J. (eds.) Management Effectiveness Evaluation in Protected Areas, A Global Study, Supplementary Report n. ${ }^{\circ}$. UICN-WCPA, WWF, Biodiversity Indicators Partnership, University of Queensland y The Nature Conservancy. pp. 82-86.

Heinrich, R., Rapoport S.M. y Rapoport T.A. 1977. Metabolic regulation and mathematical models. Prog Biophys Mol Biol 32 (1): 1-82.

Meadows, D., Jorgen, R. y Meadows, D. 2004. Los Límites del Crecimiento 30 Años Después. Círculo de Lectores S.A.U./Galaxia Gutenberg. 514 pp.

Millenium Ecosystem Assessment Panel. 2005. Ecosystems and Human Well-Being. Island Press, Washington DC. 137 pp. 
